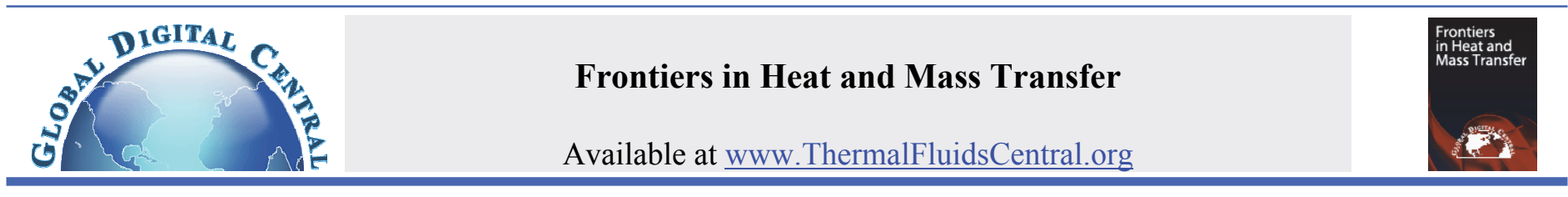

\title{
THERMAL RADIATION OF A HOT BODY OF GAS
}

\author{
Etim S. Udoetok ${ }^{*}$ \\ University of Uyo, Uyo, Akwa Ibom, Nigeria
}

\begin{abstract}
The radiation of heat by a hot body of gas is studied and a Stefan-Boltzmann kind of equation is developed. The proposed gas radiation equation is used to estimate the volumetric total emissivity of gas. The proposed total emissivity highlights the characteristics observed in published charts. The proposed gas radiation model requires the estimation of photon heat capacity from experimental data. Accurate estimation of total gas emission is very useful in applications involving combustion. Ideal gas and constant specific heats assumptions were used in the analysis for simplification.
\end{abstract}

Keywords: emissivity, heat transfer, combustion, and photons.

\section{INTRODUCTION}

Thermal radiation is a mode of heat transfer which involves the transfer of heat from one body to another by the interaction of photons between these bodies. Any of the bodies involved could be solid, liquid or gas. Thermal radiation is very important in applications involving high temperature, since the radiation from a body depends on the fourth power of its absolute temperature multiplied by the Stefan-Boltzmann constant. Due to the scale of the Stefan-Boltzmann constant, the effect of radiation becomes significant at high absolute temperatures. Therefore, heat radiation effects are very high in furnaces, combustion chambers, fires, flares and nuclear explosions (Siegel and Howell, 2002).

Thermal radiation by gases has already been a phenomenon of big interest for astronomers (Siegel and Howell, 2002). The astronomical physicists observed that during the emission or absorption of radiation by a gas, the spectrum was a characteristic of that particular gas, and could be used to determine the gas temperature and concentration. According to quantum mechanics the energy levels for atomic, molecular electron orbits, molecular rotation and vibrations are quantized. Atomic and molecular energy level can only be changed by certain quantities, so photons must have certain wavelengths to be absorbed or emitted resulting in spectral lines that is unique to a particular gas (Modest, 2003). Industrial interest in gas thermal radiation increased in the 1920's when it was found that combustion products such as carbon dioxide and water vapor are big emitters of thermal radiation (Siegel and Howell, 2002). Unlike astronomical physicist, thermal and combustion equipment scientists are more interested in the total radiation emitted from hot gases. Earliest work of measurements of radiation from hot gases was reported by Paschen in 1894 (Paschen, 1894). Thereafter, more works have been done including development of charts (Edwards and Balakrishnan, 1973; Hottel and Mangelsdorf, 1935; Hottel and Egbert, 1941; Hsieh and Greif 1972; Leckner 1972).

This paper is focused on the theoretical development of a model for gas thermal radiation from a hot body of gas. The radiation of heat from a solid surface is already well developed and captured by the basic Stefan-Boltzmann equation, which is given as

$$
E=\varepsilon \sigma T^{4}
$$

Some authors have directly adopted the Stefan-Boltzmann equation for expressing the thermal radiation from a hot body of gas (Turner, 2000; Makarov, 2015). But the direct adoption of the Stefan-Boltzmann equation comes with errors due to the difference in phase. For solids, the surface area and surface properties are the major factors, while in gases, the whole volume of the gas is involved, so this work involves relating the volume and other gas properties to the energy transport properties of photons.

\section{METHOD}

A body of gas at temperature $\mathrm{T}$ is radiating heat at a steady state can either be in the open or contained in a rigid vessel. These two cases will be analyzed separately in the next two subsections.

\subsection{Radiation of a cloud of hot gas in the open}

Assume that the cloud of hot gas is at constant pressure, say at atmospheric pressure. Photons, which transport radiation energy (Viskanta and Menguc, 1987), will enter and leave the gas cloud at the speed of light. The energy density of the photon gas has been found to be (Leff, 2002)

$$
u=\left(\frac{8 \pi^{5} k^{4}}{15 c^{3} h^{3}}\right) T^{4}
$$

Some of the photons collide with the gas molecules and attain the temperature of the gas, because the mass of the gas molecule is much bigger than that of the photon. Some photons will photons will pass without making any contact with any one of the gas molecules before exiting the cloud. The photons are assumed to be traveling at the speed of light, while the speed of the gas molecule is much smaller and depends on the temperature as given below (Bird et al, 1960; Pierce, 1968)

\footnotetext{
"Email: etim.udoetok@yahoo.com.
} 


$$
\bar{v}=\left(\frac{8 k T}{\pi m_{i}}\right)^{\frac{1}{2}}
$$

Mathematically, $c>>\bar{v}$, so the gas molecules can be assumed to be stationary hard spheres to the photons entering the gas cloud, which is in agreement with the model of stationary atoms (Vollmer, 2005; Einstein, 1917; Nauenberg, 2004). The photons colliding with the gas molecules will be reflected, deflected, or absorbed and used to attain a new energy level. Some of the deflected photons will get more deflected and temporary trapped in the gas cloud. In spite of all these, at steady state, photons enter and leave the gas at the same rate in order to conserve mass. The gas-collided photons which are assumed to have negligible initial temperature exits the gas cloud with the temperature, $T$, of the gas. The rate at which the photons which have interacted with atleast one gas molecule exits the gas cloud needs to be found. The energy radiated from the gas cloud can be give as

$$
e=\psi u=\psi\left(\frac{8 \pi^{5} k^{4}}{15 c^{3} h^{3}}\right) T^{4}
$$

where $\psi$ is the fraction of the total number of photons exiting the volume of gas. According to the first law of thermodynamics, the radiated energy lost by the gas is given as

$$
q=w+d u
$$

Eqn (5) can be rewritten as Eqn(6) since P is assumed to be constant

$$
q=d u+P d v=d h
$$

Assuming that the gas is an ideal gas, then

$$
d h=c_{p} d T
$$

where $d T$ is due to heat radiation from the hot gas cloud only. Heat loss by the gas is equal to heat carried away by the photons in order to conserve energy. Mathematically,

$$
\frac{m q}{V}=e
$$

This implies that

$$
\rho_{g} c_{p} d T=\psi\left(\frac{8 \pi^{5} k^{4}}{15 c^{3} h^{3}}\right) T^{4}
$$

There is a big difference in the rate of temperature change of the gas compared to that of the photons. Therefore, $\psi$ can be expressed as

$$
\psi=\frac{15 c^{3} h^{3} \rho_{g} c_{p} d T}{8 \pi^{5} k^{4} T^{4}}
$$

And the rate at which collided photons leave the gas cloud

$$
\phi=\psi \frac{n c}{L_{\text {char }}}
$$

Eqn. (10) into Eqn. (4) gives

$$
e=\psi u=\rho_{g} c_{p} d T
$$

and in rate form

$$
\dot{e}=\psi \frac{u c}{L_{\text {Char }}}=\psi\left(\frac{8 \pi^{5} k^{4}}{15 c^{2} h^{3} L_{\text {Char }}}\right) T^{4}=\rho_{g} c_{p} d T \frac{c}{L_{\text {Char }}}
$$

Comparing Eqn. (13) with Stefan-Boltzmann equation, Eqn. (1), the volumetric emissivity of the gas can be estimated as

$$
\varepsilon^{\prime}=\frac{4 \psi}{L_{\text {Char }}}=\frac{15 c^{3} h^{3} \rho_{g} c_{p} d T}{2 \pi^{5} L_{\text {Char }} k^{4} T^{4}}
$$

where $d T$ is the temperature drop due to radiation in the average time the photons enter and leave the gas. $d T$ and $L_{C h a r}$ can be measured experimentally.

\subsection{Radiation of a volume of hot gas in an enclosure}

For a volume of hot gas in a rigid vessel, same analysis is repeated but the first law changes. The work done in this case is zero since the volume is constant, so

$$
q=d u=c_{v} d T
$$

The emission equations become

$$
e=\psi u=\rho_{g} c_{v} d T
$$

and

$$
\dot{e}=\psi \frac{u c}{L_{\text {Char }}}=\psi\left(\frac{8 \pi^{5} k^{4}}{15 c^{2} h^{3} L_{\text {Char }}}\right) T^{4}=\rho_{g} c_{v} d T \frac{c}{L_{\text {Char }}}
$$

and the emissivity equation becomes

$$
\varepsilon^{\prime}=\frac{4 \psi}{L_{\text {Char }}}=\frac{15 c^{3} h^{3} \rho_{g} c_{v} d T}{2 \pi^{5} L_{\text {Char }} k^{4} T^{4}}
$$

For this case, heat conduction to the vessel's wall and the temperature of the wall has to be accounted for. Again, there is need to know the temperature change of the gas cloud due to heat radiation.

\section{a. Estimation of temperature change of the radiating gas}

Upon collision of the photons with gas molecule, the heat exchange can be estimated by assuming that the photons have a constant heat capacity and the new energy balance equation is given as

$$
\rho_{g} c_{p, g} d T=\psi n_{\text {photon }} \breve{c}_{p, p} T
$$

Assuming that the gas had an initial temperature $T_{g, i}$ and photon had negligible initial temperature. Upon collision, temperature will change to a common final temperature, $T_{f}$. Equation 19 can now be rewritten as

$$
\rho_{g} c_{p, g}\left(T_{g, i}-T_{f}\right)=\psi n_{\text {photon }} \breve{c}_{p, p} T_{f}
$$

This implies that the temperature change can be estimated as 


$$
d T=T_{g, i}-T_{f}=T_{g, i}\left[1-\frac{1}{1+\frac{\psi n_{p h o t o n} \breve{c}_{p, p}}{\rho_{g} c_{p, g}}}\right]
$$

There is still need to know the photon heat capacity. Therefore effort will be made in the next section to estimate these from published experimental data. Solving the simultaneous equations Eqns. (10) and (21) for $d T$ and $\psi$ gives

$$
d T=\frac{T\left(15 c^{3} h^{3} n_{p} \breve{c}_{p, p}-8 T^{3} \pi^{5} k^{4}\right)}{15 c^{3} h^{3} n_{p} \breve{c}_{p, p}}
$$

and

$$
\psi=\frac{\rho c_{p}\left(15 c^{3} h^{3} n_{p} \breve{c}_{p, p}-8 T^{3} \pi^{5} k^{4}\right)}{8 T^{3} \pi^{5} k^{4} n_{p} \breve{c}_{p, p}}
$$

where $\quad n_{p}=\frac{16 \pi k^{3} T^{3} \zeta(3)}{c^{3} h^{3}}$

\section{ESTIMATION OF TEMPERATURE CHANGE, COLLIDED PHOTON FRACTION AND PHOTON HEAT CAPACITY FROM A PUBLISHED EXPERIMENT}

Charts published by Hottel (Hottel, 1954) were used to estimate the gas temperature change, $d T$, the collided photon fraction, $\psi$ and the photon heat capacity, $\breve{c}$. The focus is on the water vapor and carbon dioxide charts where the pressure is 1 bar and partial pressure is zero.

\subsection{Gas temperature change}

Equation (14) and an assumption that the characteristic length, $L_{c h a r}$, is equal to the effective length, $L_{e}$, were used in the estimation of $d T$ from Hottel's charts. It was also assumed that $\varepsilon=\varepsilon^{\prime} L_{\text {Char }}$.

The result obtained for $\mathrm{CO}_{2}$ shows that at $P L_{e}=40 \mathrm{~atm} \mathrm{~cm}$ the temperature change is $6.9406 \times 10^{-8} \mathrm{~K}$ for $T=1000 \mathrm{~K}$ and rises to $1.25864 \times 10^{-6} \mathrm{~K}$ for $T=2200 \mathrm{~K}$. While the result for $\mathrm{H}_{2} \mathrm{O}$ showed that at $P L_{e}=40 \mathrm{~atm} \mathrm{~cm}$ the temperature change is $1.07538481 \times 10^{-7} \mathrm{~K}$ for $T$ $=1000 \mathrm{~K}$ and rises to $1.54768 \times 10^{-6} \mathrm{~K}$ for $T=2200 \mathrm{~K}$. (See Tables $1-4$ in appendix.)

The gas temperature change scale is low and would be challenging to measure, so an estimation method like Eqn. (22) may be preferable.

\subsection{Collided photon fraction}

Equation (10) and results obtained in section 3.1 were used to estimate the collided photon fraction. The result obtained for $\mathrm{CO}_{2}$ shows that at $P L_{e}=40 \mathrm{~atm} . \mathrm{cm}$ the collided photon fraction is 0.04 for $T=1000 \mathrm{~K}$ and falls to 0.0165 for $T=2200 \mathrm{~K}$. While the result for $\mathrm{H}_{2} \mathrm{O}$ showed that at $P L_{e}=40$ atm.cm the collided photon fraction is 0.071 for $T=1000 \mathrm{~K}$ and falls to 0.02375 for $T=2200 \mathrm{~K}$. (See Tables $1-4$ in appendix.)

A curve fit was generated for gas temperature range of $T=1000 \mathrm{~K}$ $-2200 \mathrm{~K}$ for the collided photon fraction. The curve fit for $\mathrm{CO}_{2}$ found is given as

$$
\psi=\frac{\ln \left(4 P L_{e}\right)}{0.04471 T^{1.138}}
$$

and the fit for $\mathrm{H} 2 \mathrm{O}$ found is given as

$$
\psi=\frac{\ln \left(P L_{e} / 2.85\right)}{0.1579 T^{0.7968}}
$$

Equations (22) and (23) combined with Eqn. (10) and Eqn. (18) eliminates the use of charts.

\subsection{Photon heat capacity}

Equation (21), and $d T$ and $\psi$ obtained with experimental data in this section were used to estimate the photon heat capacity. Approximate results were obtained for both $\mathrm{CO}_{2}$ and $\mathrm{H}_{2} \mathrm{O}$ for same temperature values. The photon heat capacity obtained is given for $\mathrm{C}_{2} \mathrm{O}$ is given as

$$
\breve{c}_{p, p}=\left(a T^{2.759891556}\right) P L_{e}+3.729248558843 \times 10^{-23}
$$

where $a=1.6924921375 \times 10^{-43}$. And the capacity found for $\mathrm{H}_{2} \mathrm{O}$ is

$$
\breve{c}_{p, p}=\left(a T^{3.197955531}\right) P L_{e}+3.729248558843 \times 10^{-23}
$$

where $a=3.8550007126 \times 10^{-45}$.

A constant value for the heat capacity was expected but the slight variation if neglected leaves a constant value that can be used for any ideal gas and is given as

$$
\breve{c}_{p, p}=3.729248558843 \times 10^{-23}
$$

Using this approximate constant will provide approximate solution of the heat emission from the hot gas.

\section{DISCUSSION}

This work deviates from Stefan-Boltzmann equation derivation at the point where $\psi$ is introduced. While Stefan-Boltzmann equivalent of $\psi$ is simply $1 / 4$ from statistical mechanics, $\psi$ for the case of gas needs more efforts since the whole gas volume is directly involved.

The proposed emissivity equation, Eqn. (14), shows that emissivity increases with increase in density which is directly proportional to pressure according to ideal gas law. It also shows that the emissivity decreases with increase in temperature. These trends are obvious in Hottel's and Leckner's charts (Hottel, 1954; Leckner, 1952). Higher gas density implies that the gas molecules are more closely distributed so more photons will collide and interact with the gas molecules. Density is directly proportional to pressure and indirectly proportional to temperature.

Estimation of radiating gas temperature change, collided photon fraction and a constant photon heat capacity provides an approximate solution for any ideal gas. Variation of heat capacity with temperature and pressure is normal, but slight variation of the photon heat capacity results in big effects on the gas radiation due to the scale of the parameters and variables involved. 13 significant figures in the photon heat capacity are also required for accurate results.

The use of experimental data from Hottel's chart showed that the gas temperature change is in the micro and nano scale, so a theoretical estimation of the temperature change or collided photon fraction is preferable. Hottel's and Leckner's chart are widely used, though experimental errors may be present (Edwards, 1976). Additionally, the experimental setups were mostly a cylindrical column of gas with radiation in the axial direction.

\section{CONCLUSIONS}

Emission equation is developed for a volume of hot gas and gas emissivity equation is further developed from this equation. The 
challenge involved estimating the rate at which photons which have interacted with the gas molecules leave the gas volume. The estimation of collided photon fraction involved assuming that photons have mass as well as heat capacity, which was estimated from published experimental data. A future improvement in the collided photon fraction equation probably from an entirely statistical mechanics approach will improve the accuracy of the proposed emission equation and eliminate dependence on experimental data.

\section{NOMENCLATURE}

$C \quad$ heat capacity $\left(\mathrm{J} / \mathrm{m}^{3} \cdot \mathrm{K}\right)$

c speed of light $(\mathrm{m} / \mathrm{s})$

$c_{p} \quad$ constant pressure specific heat $(\mathrm{J} / \mathrm{kg} \cdot \mathrm{K})$

$c_{v} \quad$ constant volume specific heat $(\mathrm{J} / \mathrm{kg} \cdot \mathrm{K})$

$\breve{c}_{P} \quad$ unit photon heat capacity $(\mathrm{J} / \mathrm{K})$

E solid surface heat emission $\left(\mathrm{W} / \mathrm{m}^{2}\right)$

e gas heat emission $\left(\mathrm{W} / \mathrm{m}^{3}\right)$

$h \quad$ Planck's constant (Js)

$d h \quad$ change in enthalpy $(\mathrm{J})$

$k \quad$ Boltzmann's constant $(\mathrm{J} / \mathrm{kg})$

$L_{\text {char }} \quad$ characteristic length (m)

Le effective length (m)

m mass $(\mathrm{kg})$

$m_{i} \quad$ molecular mass of specie $\mathrm{i}(\mathrm{kg})$

$n \quad$ number density $\left(\mathrm{m}^{-3}\right)$

$P \quad$ pressure $(\mathrm{Pa})$

$P L_{e} \quad$ pressure by effective length (bar.cm)

$q \quad$ heat transfer $(\mathrm{J} / \mathrm{kg})$

$T \quad$ temperature $(\mathrm{K})$

$d u \quad$ change in internal energy $(\mathrm{J})$

$V \quad$ volume $\left(\mathrm{m}^{3}\right)$

$\bar{v} \quad$ average velocity of molecules $(\mathrm{m} / \mathrm{s})$

$w \quad$ work $(\mathrm{J})$

\section{Greek Symbols}

$\varepsilon \quad$ total emissivity

$\varepsilon^{\prime} \quad$ total emissivity $\left(\mathrm{m}^{-1}\right)$

$\rho$ density $\left(\mathrm{kg} / \mathrm{m}^{3}\right)$

$\sigma \quad$ Stefan-Boltzmann constant $\left(\mathrm{W} / \mathrm{m}^{2} \cdot \mathrm{K}^{4}\right)$

$\psi \quad$ fraction of gas-collided photons

$\phi \quad$ rate of exit of gas-collided photons $\left(\mathrm{s}^{-1}\right)$

$\begin{array}{ll}\text { Subscripts } & \\ f & \text { final } \\ g & \text { gas } \\ i & \text { initial } \\ p & \text { photon }\end{array}$

\section{REFERENCES}

Bird, R. B., Stewart, W. E., and Lightfoot, E. N., 1960, Transport Phenomena, John Wiley \& Sons, New York

Edwards, D. K., and Balakrishnan, A., 1973, “Thermal Radiation by Combustion Gases," International Journal of Heat and Mass Transfer, 16, $25-40$

http://dx.doi.org/10.1016/0017-9310(73)90248-2

Edwards, D. K., 1976, "Thermal Radiation Measurements," in Measurements in Heat Transfer by Eckert, E. R. G., and Goldstein, ch. 10, Hemisphere, Washington, DC
Einstein, A., 1916, "Emission and Absorption of Radiation in Quantum Theory," Verhandlungen der Deutschen Physikalischen Gesellschaft, 18, 318-323

Hottel, H. C., and Mangelsdorf, H. G., 1935, "Heat Transmission by Radiation from Non-luminous Gases II. Experimental Study of Carbon Dioxide and Water Vapor," Transactions of AIChE, 31, 517-549

Hottel, H. C., and Egbert, R. B., 1941, "The Radiation of Furnace Gases," Transactions of ASME Journal of Heat Transfer, 63, 297-307

Hottel, H.C., 1954, "Radiant Heat Transmission," McAdam, H. W., Heat Transmission, $3^{\text {rd }}$ ed, ch 4, McGraw-Hill, New York

Hsieh, T. C., and Greif, R., 1972, "Theoretical Determination of the Absorption Coefficient and the Total Band Absorptance Including A Specific Application to Carbon Monoxide," International Journal of Heat and Mass Transfer, 15, 1477-1487 https://doi.org/10.1016/0017-9310(72)90005-1

Leckner, B., 1972, "Spectral and Total Emissivity of Water Vapor and Carbon Dioxide," Combustion and Flame, 19, 33-48 https://doi.org/10.1016/S0010-2180(72)80084-1

Leff, H. S., 2002, "Teaching the Photon Gas in Introductory Physics," American Journal of Physics, 70(8), 792-797

https://doi.org/10.1119/1.1479743

Makarov, A. N., 2015, "Laws of Heat Radiation from Surfaces and Gas Volumes," World Journal of Engineering and Technology, 3, 260-270 https://doi.org/10.4236/wjet.2015.34027

Modest, M. F., 2003, Radiative Heat Transfer, $2^{\text {nd }}$ ed, Academic Press, Massachusetts, USA

Nauenberg, M., 2004, "The Evolution of Radiation toward Thermal Equilibrium: A Soluble Model Which Illustrates the Foundation of Statistical Mechanics," American Journal of Physics, 72, 313-323 https://doi.org/10.1119/1.1632488

Paschen, F., 1894, Annalen der Physik und Chemie, 53, 334 https://doi.org/10.1002/andp.18942891007

Pirece, F. K., 1968, Microscopic Thermodynamics, International, Scranton, PA

Siegel, R., and Howell, J. R., 2001, Thermal Radiation Heat Transfer, $4^{\text {th }}$ ed., Taylor \& Francis, New York

Turner, R. S., 2000, An Introduction to Combustion: Concepts and Applications, $2^{\text {nd }}$ ed, McGraw-Hill, USA

Viskanta, R., and Menguc, M. P., 1987, "Radiation Heat Transfer in Combustion Systems,” Prog. Energy Combust. Sci., 13, 97-160 https://doi.org/10.1016/0360-1285(87)90008-6

Vollmer, M., 2005, "Hot Gases: The Transition from Line Spectra to Thermal Radiation," American Journal of Physics, 73, 215-223 https://doi.org/10.1119/1.1819931

\section{APPENDIX}

The following are selected tables used in the estimation of gas temperature change, collided photon fraction and photon heat capacity. Total emissivity and $P L_{e}$ are from Hottel's charts, while $d T, \psi$, and $\breve{c}_{P}$ are from equations developed in this work. The pressure is 1 bar and partial pressure is zero. 
Table 1: Emission data for $\mathrm{CO}_{2}$ at $\mathrm{T}=1000 \mathrm{~K}$

\begin{tabular}{|l|l|l|l|l|}
\hline$\varepsilon$ & $\begin{array}{l}\mathrm{PLe} \\
(\mathrm{atm}-\mathrm{cm})\end{array}$ & $\mathrm{dT}(\mathrm{K})$ & $\psi$ & $\breve{c}_{p, p}(\mathrm{~J} / \mathrm{K})$ \\
\hline 0.005 & 0.05 & $2.1689 \mathrm{E}-09$ & 0.00125 & $3.7292485583317 \mathrm{E}-23$ \\
\hline 0.013 & 0.15 & $5.6392 \mathrm{E}-09$ & 0.00325 & $3.7292485583446 \mathrm{E}-23$ \\
\hline 0.029 & 0.3 & $1.2579 \mathrm{E}-08$ & 0.00725 & $3.7292485583705 \mathrm{E}-23$ \\
\hline 0.038 & 0.6 & $1.6483 \mathrm{E}-08$ & 0.0095 & $3.7292485583850 \mathrm{E}-23$ \\
\hline 0.046 & 1 & $1.9954 \mathrm{E}-08$ & 0.0115 & $3.7292485583980 \mathrm{E}-23$ \\
\hline 0.058 & 2 & $2.5159 \mathrm{E}-08$ & 0.0145 & $3.7292485584174 \mathrm{E}-23$ \\
\hline 0.077 & 4 & $3.3401 \mathrm{E}-08$ & 0.01925 & $3.7292485584481 \mathrm{E}-23$ \\
\hline 0.095 & 8 & $4.1209 \mathrm{E}-08$ & 0.02375 & $3.7292485584773 \mathrm{E}-23$ \\
\hline 0.12 & 15 & $5.2054 \mathrm{E}-08$ & 0.03 & $3.7292485585177 \mathrm{E}-23$ \\
\hline 0.16 & 40 & $6.9406 \mathrm{E}-08$ & 0.04 & $3.7292485585824 \mathrm{E}-23$ \\
\hline 0.2 & 100 & $8.6757 \mathrm{E}-08$ & 0.05 & $3.7292485586471 \mathrm{E}-23$ \\
\hline
\end{tabular}

Table 2: Emission data for $\mathrm{CO}_{2}$ at $\mathrm{T}=2200 \mathrm{~K}$

\begin{tabular}{|l|l|l|l|l|}
\hline$\varepsilon$ & $\begin{array}{l}\mathrm{PL}_{\mathrm{e}} \\
(\mathrm{atm}-\mathrm{cm})\end{array}$ & $\mathrm{dT}(\mathrm{K})$ & $\psi$ & $\breve{c}_{p, p}(\mathrm{~J} / \mathrm{K})$ \\
\hline 0.000125 & 0.15 & $2.3838 \mathrm{E}-09$ & 0.00003125 & $3.72924855833 \mathrm{E}-23$ \\
\hline 0.006 & 0.3 & $1.1442 \mathrm{E}-07$ & 0.0015 & $3.72924855852 \mathrm{E}-23$ \\
\hline 0.0093 & 0.6 & $1.7735 \mathrm{E}-07$ & 0.002325 & $3.72924855862 \mathrm{E}-23$ \\
\hline 0.015 & 1 & $2.8605 \mathrm{E}-07$ & 0.00375 & $3.72924855881 \mathrm{E}-23$ \\
\hline 0.024 & 2 & $4.5769 \mathrm{E}-07$ & 0.006 & $3.72924855910 \mathrm{E}-23$ \\
\hline 0.031 & 4 & $5.9118 \mathrm{E}-07$ & 0.00775 & $3.72924855933 \mathrm{E}-23$ \\
\hline 0.039 & 8 & $7.4374 \mathrm{E}-07$ & 0.00975 & $3.72924855958 \mathrm{E}-23$ \\
\hline 0.045 & 15 & $8.5816 \mathrm{E}-07$ & 0.01125 & $3.72924855978 \mathrm{E}-23$ \\
\hline 0.066 & 40 & $1.2586 \mathrm{E}-06$ & 0.0165 & $3.72924856046 \mathrm{E}-23$ \\
\hline 0.089 & 100 & $1.6973 \mathrm{E}-06$ & 0.02225 & $3.72924856120 \mathrm{E}-23$ \\
\hline
\end{tabular}

Table 3: Emission data for $\mathrm{H}_{2} \mathrm{O}$ at $\mathrm{T}=1000 \mathrm{~K}$

\begin{tabular}{|l|l|l|l|l|}
\hline$\varepsilon$ & $\begin{array}{l}\mathrm{PL}_{\mathrm{e}} \\
(\mathrm{atm}-\mathrm{m})\end{array}$ & $\mathrm{dT}(\mathrm{K})$ & $\psi$ & $\breve{c}_{p, p}(\mathrm{~J} / \mathrm{K})$ \\
\hline 0.009 & 0.5 & $3.4079 \mathrm{E}-09$ & 0.00225 & $3.729248558336 \mathrm{E}-23$ \\
\hline & & & & \\
\hline 0.03 & 1.5 & $1.1360 \mathrm{E}-08$ & 0.0075 & $3.729248558366 \mathrm{E}-23$ \\
\hline 0.044 & 3 & $1.6661 \mathrm{E}-08$ & 0.011 & $3.729248558386 \mathrm{E}-23$ \\
\hline 0.07 & 6 & $2.6506 \mathrm{E}-08$ & 0.0175 & $3.729248558422 \mathrm{E}-23$ \\
\hline 0.1 & 10 & $3.7866 \mathrm{E}-08$ & 0.025 & $3.729248558465 \mathrm{E}-23$ \\
\hline 0.18 & 20 & $6.8158 \mathrm{E}-08$ & 0.045 & $3.729248558578 \mathrm{E}-23$ \\
\hline 0.284 & 40 & $1.0754 \mathrm{E}-07$ & 0.071 & $3.729248558725 \mathrm{E}-23$ \\
\hline 0.34 & 80 & $1.2874 \mathrm{E}-07$ & 0.085 & $3.729248558804 \mathrm{E}-23$ \\
\hline 0.404 & 150 & $1.5298 \mathrm{E}-07$ & 0.101 & $3.729248558894 \mathrm{E}-23$ \\
\hline 0.46 & 400 & $1.7418 \mathrm{E}-07$ & 0.115 & $3.729248558973 \mathrm{E}-23$ \\
\hline
\end{tabular}

Table 4: Emission data for $\mathrm{H}_{2} \mathrm{O}$ at $\mathrm{T}=2200 \mathrm{~K}$

\begin{tabular}{|l|l|l|l|l|}
\hline$\varepsilon$ & $\begin{array}{l}\text { PLe } \\
(\text { atm-cm })\end{array}$ & $\mathrm{dT}(\mathrm{K})$ & $\psi$ & $\breve{c}_{p, p}(\mathrm{~J} / \mathrm{K})$ \\
\hline 0.012 & 3 & $1.9550 \mathrm{E}-07$ & 0.003 & $3.7292485587 \mathrm{E}-23$ \\
\hline 0.028 & 6 & $4.5616 \mathrm{E}-07$ & 0.007 & $3.7292485591 \mathrm{E}-23$ \\
\hline 0.037 & 10 & $6.0278 \mathrm{E}-07$ & 0.00925 & $3.7292485593 \mathrm{E}-23$ \\
\hline 0.06 & 20 & $9.7748 \mathrm{E}-07$ & 0.015 & $3.7292485600 \mathrm{E}-23$ \\
\hline 0.095 & 40 & $1.5477 \mathrm{E}-06$ & 0.02375 & $3.7292485609 \mathrm{E}-23$ \\
\hline 0.16 & 80 & $2.6066 \mathrm{E}-06$ & 0.04 & $3.7292485627 \mathrm{E}-23$ \\
\hline 0.22 & 150 & $3.5841 \mathrm{E}-06$ & 0.055 & $3.7292485644 \mathrm{E}-23$ \\
\hline 0.29 & 400 & $4.7245 \mathrm{E}-06$ & 0.0725 & $3.7292485663 \mathrm{E}-23$ \\
\hline
\end{tabular}

